\title{
Influence of incubation management on pipping position, hatching ability and survival of ostrich chicks
}

\author{
Z. Brand ${ }^{1,2 \#}$, S.W.P. Cloete ${ }^{2,3}$, I.A. Malecki ${ }^{4}$ \& C.R. Brown ${ }^{5}$ \\ ${ }^{1}$ Department of Animal Sciences, University of Stellenbosch, Private Bag X1, Matieland, 7602, South Africa \\ ${ }^{2}$ Institute for Animal Production, PO Box 351, Oudtshoorn, 6220, South Africa \\ ${ }^{3}$ Institute for Animal Production, Private Bag X1, Elsenburg, 7607, South Africa \\ ${ }^{4}$ School of Animal Biology, Faculty of Natural and Agricultural Science, University of Western Australia, Crawley, \\ 6009, Australia \\ ${ }^{5}$ Institute of Science and the Environment, University of Worcester, Henwick Grove, Worcester, WR2 6AJ, England
}

Copyright resides with the authors in terms of the Creative Commons Attribution 2.5 South African Licence.

See: http://creativecommons.org/licenses/by/2.5/za

Condition of use: The user may copy, distribute, transmit and adapt the work, but must recognise the authors and the South African Journal of Animal Science.

\begin{abstract}
Despite numerous studies, the effect of artificial incubation on the hatchability and survival of nearterm ostrich chicks is still not well understood. Records from 13975 eggs with embryos of 35 days and older, artificially incubated between 2006 and 2008, were analysed to determine the potential effect of pipping position upon the hatchability, and the subsequent survival of ostrich chicks. A total of 864 nearterm chicks $(6.9 \%)$ failed to pip. Chicks that pipped in the correct position had a higher probability of surviving hatching than those pipping in the incorrect position. Genotype did not affect the proportion of chicks pipping in the correct position, or the survival of hatching ostrich chicks pipping in either the correct or incorrect positions. Although female age had a significant effect on the proportion of chicks pipping, the survival of hatchlings was independent of female age. Chicks hatching during winter were more likely to pip than chicks hatching in spring, whereas chicks hatching in summer were more likely to pip in the correct position. In winter the proportion of chicks pipping in incorrect positions were significantly higher than in either summer or autumn. The survival rate of chicks hatching during winter was generally higher than those hatching in the other seasons. The transfer of eggs between setters during incubation, had a negative influence on the ability of ostrich chicks pipping in the correct position. Incubated ostrich eggs with intermediate levels of water loss, i.e. between 9.0 and $18.9 \%$ of fresh-egg weight, were more likely to pip in the correct position overall than those with higher or lower levels of water loss. Chicks from eggs stored for intermediate periods, i.e. 3, 4 and 6 days prior to being set, were more likely to pip than chicks from those eggs set directly after collection without storage. Storage time also affected pipping position, with chicks from eggs stored for five days being more likely to pip in the correct position than chicks from those eggs set directly after collection. These results emphasize the need for ostrich incubation facilities to avoid the transfer of eggs between setters during artificial incubation, strive to achieve an optimal level of water loss, and apply a protocol of not setting eggs immediately after collection to maximize the hatchability of chicks pipping in the correct position and post-hatching survival.
\end{abstract}

Keywords: Ratite, artificial incubation, female age, water loss, storage time

${ }^{\#}$ Corresponding author: zanellb@elsenburg.com

\section{Introduction}

Despite being a well-established livestock industry, the production of ostriches does not compare well with more conventional domesticated poultry species. The artificial incubation of ostrich eggs is poorly understood when compared with poultry. The low hatchability of artificially-incubated eggs is considered to be one of the constraints in the production efficiency of commercial ostrich production systems worldwide (Deeming, 1995a). According to Deeming et al. (1993), a lack of understanding of the pattern of embryonic development, especially factors affecting the pipping position just prior to hatching, contributes to the high incidence of embryonic mortalities during this period. 
The malposition of embryos with respect to the air cell generally results in failure to hatch (Brown et al., 1996). Developing ostrich chicks start turning in the egg to assume the correct pipping position from day 35 of incubation and have usually assumed the correct pipping position by day 42 of incubation (Deeming, 1995b). At this stage, the neck of the chick lies from left to right with the right foot next to the beak and the left foot positioned by the nape of the neck. This pipping position differs from that of the domestic fowl (Deeming, 1994). The most common malposition for ostrich embryos is that of the head at the opposite end of the air cell (malposition 2 for chickens). Chicks presented in this position die because they are unable to penetrate the air cell, but a small percentage of embryos may pip at the bottom of the egg and still survive. The embryo may also be positioned with its head to the left side instead of the right side. Other abnormalities observed include having the foot positioned under the head, while some chicks get their head stuck across their right leg or the right foot gets stuck over the head or in the beak (Deeming, 1995b).

Van Schalkwyk et al. (1996) found that more than 70\% of all dead-in-shell cases occur during the pipping stage, mainly due to inadequate incubation equipment, which results in high relative humidity, overheating and inadequate hygiene management. Brown et al. (1996) reported that more than 55\% of shell deaths in ostrich eggs is due to malpositions of the embryo. This observation was confirmed in a study by Ipek \& Sahan (2004). Successful artificial incubation is also affected by a number of factors including female age, season, and storage conditions of eggs prior to setting in the incubator, as well as the type of incubator (Blood, 1998; Van Schalkwyk, 1999; Brand et al., 2007; Brand, et al., 2008a). Egg production of ostrich females starts at $2-2.5$ years of age and peak egg and chick production occurs at $8-9$ years. Female age, however, is known to influence the number of eggs laid as well as egg weight and, consequently, chick weight at hatching (Bunter \& Cloete, 2004; Ipek \& Sahan, 2004; Lambrechts, 2004; Cloete et al., 2006a; Brand et al., 2007). Embryonic deaths during both the first half and the second half of incubation were proportionally increased in older females, the effect being more pronounced for deaths during the second half of incubation (Brand et al., 2007).

Hassan et al. (2005) reported that the storage period affected egg weight loss, while Deeming (1993) determined that an increase of storage time resulted in a reduction of embryo vitality. The storage of ostrich eggs for periods longer than seven days, results in an increase of embryonic mortality (Wilson et al., 1997; Brand et al., 2007). Results from studies by Deeming (1995a), Ar (1996) and Blood et al. (1998) showed that the optimal water loss for artificially-incubated ostrich eggs amounts to approximately $15 \%$ but, like other birds, ostriches show some latitude in the amount of water loss at which eggs will still hatch successfully. Eggs which lost less than $10 \%$ or more than $20 \%$ of their initial weight were less likely to hatch. Excessive water loss during incubation causes early depletion of allantoic fluids, which results in the subsequent dehydration of the embryo and extends the period of osmotic stress (Davis et al., 1988). On the other hand, the insufficient water loss from the egg results in water retention in the chick, potentially causing embryonic mortality through respiratory insufficiency (Musara et al., 1999). It also results in a high proportion of chicks being malpositioned at the point of hatching or in unabsorbed yolk sacs (Horbaňczuk et al., 1999). Malpositioning generally resulted from incorrect turning, and oedema was significantly related to the quantity of water lost (Brown et al., 1996).

When introducing different genotypes into an ostrich breeding flock, the effect of cross-breeding on egg production and fertility needs to be considered. Embryonic mortality as a result of genetic problems can compromise hatchability, but such an effect has not yet been recorded in ostriches (Badley, 1997). In a study involving the South African Black and Zimbabwean Blue breeds and their crosses, there was some evidence supporting the existence of genotypic differences (Brand et al., 2007).

A better understanding of how systematic factors influence the successful artificial incubation of ostrich eggs is essential (Cloete et al., 2002), especially during the crucial last few days of incubation when chicks move into the correct position for hatching. The aim of this study was thus to investigate the effects of environmental factors such as production year, season, female age, genotype, water loss, the incubator type used as well as storage time on the proportions of eggs pipping, the pipping of eggs in the correct position, as well as survival of chicks, in eggs pipped in both the correct and incorrect positions.

\section{Material and Methods}

Eggs were obtained from the commercial ostrich breeding flock maintained at the Oudtshoorn Research farm, in the Klein Karoo region of South Africa. The origin of the ostrich flock and general husbandry of the breeding flock has been well described by Van Schalkwyk, et al. (1996) and Bunter \& 
Cloete (2004). Data for this study was collected during the 2006, 2007 and 2008 breeding seasons. Unless specified otherwise, each breeding bird received a ration of 2.5 to $3 \mathrm{~kg} \mathrm{DM} / \mathrm{bird} /$ day throughout the breeding season, which commenced at the beginning of June, and lasted till the end of January in 2006 and 2007. The exception was in 2008, when the breeding season started mid-May and ended mid-December.

Eggs were collected daily, weighed and identified by date and paddock of origin. Methods for collection, sanitation and storage at the experimental site are well documented (Van Schalkwyk et al., 1998; Van Schalkwyk et al., 1999; Bunter \& Cloete, 2004; Brand et al., 2007). At the beginning and end of the season, however, there were insufficient eggs to occupy the available incubator space optimally. These eggs were consequently stored for periods not exceeding 20 days. Eggs were artificially incubated at $36{ }^{\circ} \mathrm{C}$ and $24 \%$ relative humidity (RH) in Buckeye ${ }^{\circledR}$, Prohatch ${ }^{\circledR}$ or African International ${ }^{\circledR}$ incubators and all incubators were set to turn eggs automatically through an angle of $60-90$ degrees on an hourly basis. The capacity and operation of the Buckeye ${ }^{\circledR}$ and Prohatch ${ }^{\circledR}$ incubators are described by Cloete et al. (2001) and the African Incubator ${ }^{\circledR}$ is described by Brand et al. (2007). On day 35 of incubation, the eggs were transferred from the setters to a Prohatch ${ }^{\circledR}$ hatcher, which also operated at $36^{\circ} \mathrm{C}$ and a $\mathrm{RH}$ of $24 \%$. Eggs were set vertically with their air sacs positioned upwards in the hatcher and from this stage the eggs were not turned again. Eggs were checked twice daily to see whether external pipping had occurred. Eggs with signs of external pipping were transferred to a second hatcher, a Buckeye ${ }^{\circledR}$, to facilitate identification of the chicks. The external pipping position of each egg was also recorded to assess whether chicks pipped in the correct position. All eggs, where external pipping occurred around the air sac area, were classified as having been pipped in the correct position, whereas eggs where pipping occurred towards the middle or bottom of the egg were classified as having been pipped in the incorrect position. On day 44 of incubation, eggs that did not hatch were candled to see if any movement could be detected, thus indicating whether internal pipping had/had not occurred. These eggs were manually opened at the air sac area, and the position of the embryo and point of internal pipping noted.

During 2003 Zimbabwean Blue (ZB) breeders were introduced to the flock and mated in various combinations with South African Black (SAB) males and SAB females (Brand et al., 2005). During 2007 Kenyan Redneck (KAR) breeding birds were introduced to the flock and mated with SAB females. Data recorded in 2006 thus involved various combinations of the two pure-bred bloodlines (SAB and ZB) as well as the reciprocal crosses between them, while data recorded in 2007 included combinations of the third purebred bloodline (KAR) as well as KAR males mated to SAB females.

A total of 23709 eggs with pedigrees were collected during the three breeding seasons. Eggs were excluded from analyses if they had a defect, i.e. holes in the shell or dull shells that prevented them from being set (1314), or had embryos that died before 21 days of incubation (1342). Rotten eggs (840) and infertile eggs (5629) were used in other experiments (830). A further 1101 eggs were excluded because subsequent inspection of the dead-in-shell chicks showed they had died between 21 and 35 days of incubation, which is prior to the stage where embryos are expected to begin orientating into the correct position for pipping and when malpositioning becomes evident. Only records from eggs with chicks of 35 days and older were thus used. A further 12 records, with uncertain pipping data, were also excluded. The final number of eggs analysed was thus 12659, of which 2675 died after 35 days of incubation (21.1\%). A further 864 eggs (6.9\%) had not pipped externally and were excluded from all analyses involving pipped eggs. Some analyses contained slightly fewer eggs, e.g. in assessing the effect of genotype because genotypes represented by very low numbers were excluded from the analysis.

Data was classified into three categories, i.e. chicks that pipped successfully, chicks that pipped in the correct position and chicks that pipped in the incorrect position. The latter two categories were further divided into chicks that survived after pipping and those that succumbed in the period after pipping. Chisquare procedures (Van Ark, 1990) were used to assess the effects of genotype, female age, season, incubator, year, water loss and storage time on the incidence of pipping ostrich chicks, the number of chicks pipping in the correct or incorrect position, as well as the subsequent survival of hatching in chicks pipping in the correct or incorrect positions.

\section{Results and Discussion}

The position of chicks, from eggs that failed to hatch, will be dealt with in a separate study. Chicks hatching from eggs pipped in the correct position $(9841 / 10526=0.935)$ had a significantly higher survival rate than chicks that hatched from eggs pipped in the incorrect position $(436 / 1254=0.348 ; P<0.01)$. 
The results of the present study indicated that genotype had no significant effect on the proportion of chicks that pipped, the proportion of chicks that pipped in the correct position or the survival of chicks that pipped in the correct position (Table 1). These results suggest that the crossing of different strains of breeders can be done without compromising the hatchability of late-term eggs ( $\geq 35$ days of incubation). An impaired hatchability due to embryonic mortality as a result of genetic problems, may compromise chick production in poultry, but such an effect has not yet been reported in ostriches (Badley, 1997). Brown et al. (1996) suggested that malpositioning of ostrich embryos with respect to the air cell could possibly be related to genetic factors. Brand et al. (2007) reported an unexpectedly high level of overall embryonic deaths in the progeny of $\mathrm{SAB}$ males mated to $\mathrm{ZB}$ females. This was surprising, especially since the best hatchability results in absolute terms, were achieved in the reciprocal cross.

The influence of season on the pipping frequency of eggs is shown in Table 2. During winter and summer the proportion of chicks that pipped $(0.950$ and 0.942 , respectively) was higher $(P<0.05)$ than in eggs that hatched during the spring (0.915). A possible contributing factor is changes in eggshell structure, but more research is required to determine whether seasonal changes in eggshell structure (as determined by the female) contributed to a lower pipping proportion during spring. Previous research suggested the possibility that the eggshell characteristics of females may compensate for climatic conditions to ensure a relative constant water loss (Cloete et al., 2006b).

The proportion of chicks pipping in the correct position was higher during summer (0.921), while the survival of chicks that pipped in the correct position was higher during winter (0.947). The survival of chicks from eggs pipped in the incorrect position was significantly higher for the winter at $42.2 \%$, followed by spring and then by summer at $32.8 \%$ and $19.0 \%$, respectively. The seasonal differences in the pipping performance of near-term ostrich chicks seemed to be conflicting in some instances, e.g. the poor survival of chicks that pipped during summer seems to be in conflict with the generally better pipping performance in this season. No comparable literature in other avian species could be found and it is too early to speculate about a possible underlying cause for this phenomenon without further investigation.

With respect to overall shell deaths, Brand et al. (2007) found that chicks hatched from eggs produced in the southern hemisphere at the beginning of the breeding season, namely during winter, were more likely to succumb prior to hatching this proportion was reduced towards the end of the breeding season during summer. The latter results differed from those of Wilson et al. (1997) in that hatchability for set eggs

Table 1 The influence of genotype on the pipping success, pipping position and subsequent survival of chicks hatched from eggs produced during the 2006, 2007 and 2008 breeding seasons (frequency in brackets)

\begin{tabular}{|c|c|c|c|c|c|}
\hline \multirow[b]{2}{*}{ Genotype } & \multicolumn{5}{|c|}{ Category } \\
\hline & Number of eggs & Eggs pipped & $\begin{array}{l}\text { Pipped in } \\
\text { correct position }\end{array}$ & $\begin{array}{c}\text { Survival of } \\
\text { chicks pipped in } \\
\text { correct position }\end{array}$ & $\begin{array}{l}\text { Survival of chicks } \\
\text { pipped in } \\
\text { incorrect position }\end{array}$ \\
\hline Overall & 12270 & $11433(0.932)$ & $10225(0.894)$ & $9560(0.935)$ & $424(0.351)$ \\
\hline Black $\hat{\text { ô }} \mathrm{x}$ Black $q$ & 8184 & $7601(0.932)$ & $6772(0.891)$ & $6325(0.934)$ & $274(0.331)$ \\
\hline Blue $\widehat{o}$ x Blue ${ }^{+}$ & 456 & $419(0.919)$ & $376(0.897)$ & $357(0.949)$ & $21(0.488)$ \\
\hline Blue $\widehat{~} x^{x}$ Black $q$ & 1238 & $1174(0.948)$ & $1045(0.890)$ & $985(0.943)$ & 45 (0.349) \\
\hline Black $\widehat{\jmath}$ x Blue & 407 & $371(0.912)$ & $346(0.933)$ & $323(0.934)$ & $11(0.440)$ \\
\hline Black ${ }^{\lambda} \mathrm{x}$ BlBk $q$ & 1078 & $1005(0.932)$ & $902(0.898)$ & $834(0.925)$ & $39(0.379)$ \\
\hline Black $\widehat{o}$ x BkBl $q$ & 490 & $466(0.951)$ & $434(0.931)$ & $418(0.963)$ & $12(0.375)$ \\
\hline $\operatorname{Red} \hat{\partial} \mathrm{x} \operatorname{Red} \varphi$ & 160 & $147(0.919)$ & $129(0.878)$ & $115(0.891)$ & $5(0.278)$ \\
\hline Red $\widehat{o} \times$ Black $q$ & 257 & $250(0.973)$ & $221(0.884)$ & $207(0.937)$ & $17(0.586)$ \\
\hline $\mathrm{Chi}^{2}$ & & 20.385 & 14.522 & 13.827 & 13.854 \\
\hline
\end{tabular}

Critical $\mathrm{Chi}^{2}(P=0.05)$ for 6 degrees of freedom $=14.067$. 
Table 2 Influence of season on the pipping success, pipping position, and survival of chicks hatched from eggs produced in the southern hemisphere

\begin{tabular}{lccccc}
\hline Season & Number of eggs & Eggs pipped & $\begin{array}{c}\text { Pipped in correct } \\
\text { position }\end{array}$ & $\begin{array}{c}\text { Survival of } \\
\text { chicks pipped in } \\
\text { correct position }\end{array}$ & $\begin{array}{c}\text { Survival of } \\
\text { chicks pipped in } \\
\text { incorrect } \\
\text { position }\end{array}$ \\
\cline { 2 - 6 } Overall & 12659 & $11780(0.931)$ & $10526(0.894)$ & $9842(0.935)$ & $818(0.652)$ \\
Winter & 4286 & $4071\left(0.950^{\mathrm{a}}\right)$ & $3634\left(0.893^{\mathrm{a}}\right)$ & $3441\left(0.947^{\mathrm{a}}\right)$ & $187\left(0.428^{\mathrm{a}}\right)$ \\
Spring & 6530 & $5972\left(0.915^{\mathrm{b}}\right)$ & $5292\left(0.886^{\mathrm{a}}\right)$ & $4922\left(0.930^{\mathrm{b}}\right)$ & $223\left(0.328^{\mathrm{b}}\right)$ \\
Summer & 1843 & $1737\left(0.942^{\mathrm{a}}\right)$ & $1600\left(0.921^{\mathrm{b}}\right)$ & $1480\left(0.925^{\mathrm{b}}\right)$ & $26\left(0.190^{\mathrm{c}}\right)$ \\
$\mathrm{Chi}^{2}$ & & 54.613 & 17.375 & 13.512 & 28.633 \\
\hline
\end{tabular}

Critical $\mathrm{Chi}^{2}(P=0.05)$ for 6 degrees of freedom $=5.991$.

${ }_{\mathrm{a}, \mathrm{b}, \mathrm{c}}$ Denote significant $(P<0.05)$ differences in columns between frequencies in brackets.

decreased linearly as the breeding season progressed. His study was conducted in the northern hemisphere in Florida. The winter season also seems to generate the best hatching results for duck eggs, with low rainfall and suitable room temperatures as the main contributing factors for this result (Chowdhury et al., 2004). It could be speculated that the cold weather in winter had an influence on hatchability, due to the marked decrease in temperature during night-time eggs collected in the mornings were quite wet from dew forming on the outer eggshell.

The traits investigated in this study were mostly independent of female age, with the only significant difference observed for eggs produced by 3 -year old females that were more likely to pip than eggs produced by females at nine years of age (Table 3$)(P<0.05)$. Bunter $(2002)$ and Cloete et al. (2006a) reported that, although older ostrich females are still capable of good egg production, chick production declined overall due to higher levels of embryonic mortality. The findings of this study failed to support the findings of Brand et al. (2007), who reported that fertile eggs produced by older females are less likely to hatch than eggs produced by younger females. It was postulated by Brand et al. (2007) that higher shell deaths in older females were possibly related to changes in egg weight and shell quality, which presumably influence the hatchability of eggs through other factors such as water loss, with a more distinct impact on shell deaths earlier in incubation. The present study suggests that the survival of hatching of near-term ostrich chicks is probably not as dependent on female age as embryonic death occurring at earlier ages.

Despite the fact that all incubators were adjusted and set to provide the same incubation and hatching conditions, the frequency of chicks that pipped in the correct position differed $(P<0.05)$ between incubators, due to the lower pipping frequency of chicks in those eggs transferred between incubators compared to chicks from eggs incubated throughout in a single incubator (Table 4). The survival of chicks pipping in the correct position was higher in the Buckeye ${ }^{\circledR}$ incubator, compared to chicks hatching from eggs transferred between incubators $(P<0.05)$, although the observed effect was quite small $(1.5 \%)$. A contradictory effect was observed when the survival of small numbers of chicks pipping in the incorrect position was considered, which was higher in those chicks from eggs incubated in more than one incubator compared to the Buckeye ${ }^{\circledR}$ incubator. It also seems that arguments in favour of an impaired pipping ability, due to more frequent handling of transferred eggs, do not seem to be valid, for such transfers are usually performed during routine husbandry procedures like candling. Eggs returned to the same incubator are thus also subjected to the same set of procedures as those returned to other incubators. No apparent explanations can be provided for these results.

A significant effect of production year on malpositioning and survival of ostrich chicks was observed, with the overall proportion of chicks pipping in 2007 (0.940) and 2008 (0.944) being higher than in those eggs that pipped in 2006 (0.913; Table 5). The proportion of chicks pipping in the correct position, as well as the survival of chicks that pipped in the incorrect position, was higher during the 2006 and 2007 breeding 
seasons; 0.897 and 0.909 , respectively, when compared to the 2008 breeding season at $0.880(P<0.05)$. There was no difference between years for the survival of hatching in chicks pipping in the correct position.

Table 3 Influence of female age on the pipping success, pipping position, and survival of chicks hatched from eggs produced in the southern hemisphere

\begin{tabular}{|c|c|c|c|c|c|}
\hline \multirow[b]{2}{*}{ Age } & \multicolumn{5}{|c|}{ Category } \\
\hline & Number of eggs & Eggs pipped & $\begin{array}{l}\text { Pipped in correct } \\
\text { position }\end{array}$ & $\begin{array}{c}\text { Survival of } \\
\text { chicks pipped in } \\
\text { correct position }\end{array}$ & $\begin{array}{c}\text { Survival of } \\
\text { chicks pipped in } \\
\text { incorrect } \\
\text { position } \\
\end{array}$ \\
\hline Overall & 12049 & $11231(0.932)$ & $10027(0.893)$ & $9375(0.935)$ & $787(0.654)$ \\
\hline 2 years & 1268 & $1195\left(0.942^{\mathrm{ab}}\right)$ & $1079(0.903)$ & $1026(0.951)$ & $75(0.647)$ \\
\hline 3 years & 2421 & $2278\left(0.941^{b}\right)$ & $2055(0.902)$ & $1940(0.944)$ & $129(0.578)$ \\
\hline 4 years & 1733 & $1608\left(0.928^{\mathrm{ab}}\right)$ & $1442(0.897)$ & $1350(0.936)$ & $105(0.633)$ \\
\hline 5 years & 1781 & $1670\left(0.938^{\mathrm{ab}}\right)$ & $1475(0.883)$ & $1369(0.928)$ & $134(0.687)$ \\
\hline 6 years & 1073 & $997\left(0.929^{\mathrm{ab}}\right)$ & $891(0.894)$ & $825(0.926)$ & $96(0.651)$ \\
\hline 7 years & 1079 & $994\left(0.921^{\mathrm{ab}}\right)$ & $888(0.893)$ & 834 (0.939) & $72(0.679)$ \\
\hline 8 years & 806 & $753\left(0.934^{\mathrm{ab}}\right)$ & $658(0.874)$ & $617(0.938)$ & $62(0.653)$ \\
\hline 9 years & 644 & $581\left(0.902^{\mathrm{a}}\right)$ & $520(0.895)$ & $474(0.912)$ & $42(0.689)$ \\
\hline $10+$ years & 1244 & $1155\left(0.928^{\mathrm{ab}}\right)$ & $1019(0.882)$ & $946(0.928)$ & $99(0.728)$ \\
\hline $\mathrm{Chi}^{2}$ & & 18.084 & 9.416 & 15.149 & 10.842 \\
\hline
\end{tabular}

Critical $\mathrm{Chi}^{2}(P=0.05)$ for 6 degrees of freedom $=15.507$.

${ }^{\mathrm{a}, \mathrm{b}}$ Denote significant $(P<0.05)$ differences in columns between frequencies in brackets.

Even though year affected the hatchability of ostrich eggs, year effects are generally inconsistent and unpredictable, and unlikely to be repeated during consecutive years (Brand et al., 2007). Factors such as climatic conditions, variation in the chemical composition of the raw materials used to formulate diets and changes in husbandry practices, may all contribute to the potential variation between years. Although eggs in the process of incubation are shielded against changes in, e.g. atmospheric climatic conditions by controlling the incubation environment, it is possible that the exposure of eggs to the elements prior to incubation may influence hatchability. However, the impact of the mentioned effects on the hatchability of ostrich eggs is poorly understood and needs to be investigated on a larger scale and in a longer time frame (Malecki et al., 2005).

There were significant differences in pipping position and survival of hatched chicks for different levels of water loss (WL) to 35 days of incubation (Table 6). The pipping frequency of incubated eggs, as well as survival of chicks, both from chicks pipping in the correct or incorrect positions were lowest for those eggs where moisture loss was either below $9 \%$ or above $19 \%$ during the first 35 days of incubation, i.e. these traits had an intermediate optimum. These results coincide with findings by Deeming (1995a) that patterns of survival beyond day 35 of incubation were closely linked with variation in the quantity of weight lost by eggs. Brown et al. (1996) and Badley (1997) hypothesized that malpositioning of embryos may be caused by insufficient water loss. Insufficient water loss results in oedema which usually causes impaired oxygen diffusion across the moist shell membranes (Brown et al., 1996). In contrast, excessive water loss results in dehydration of the embryos and the drying out of shell membranes (Brown et al., 1996). Deeming (1995a) found that the pattern of mortality in chicks surviving beyond day 36 of incubation, was closely linked to the degree of variation in the amount of water lost from the egg. Deeming (1995b) reported a significant relationship between percentage weight loss and the location of the pipping hole. As water loss increased, the pipping hole was more likely to be situated closer to the equator of the egg. 
Table 4 The influence of incubator on the pipping success, pipping position, and survival of chicks hatched from eggs produced during three consecutive breeding seasons

\begin{tabular}{lccccc}
\hline & \multicolumn{5}{c}{ Category } \\
\cline { 2 - 5 } Incubator & Number of eggs & Eggs pipped & $\begin{array}{c}\text { Pipped in correct } \\
\text { position }\end{array}$ & $\begin{array}{c}\text { Survival of } \\
\text { chicks pipped in } \\
\text { correct position }\end{array}$ & $\begin{array}{c}\text { Survival of } \\
\text { chicks pipped in } \\
\text { incorrect } \\
\text { position }\end{array}$ \\
\hline Overall & 12651 & $11778(0.931)$ & $10524(0.894)$ & $9840(0.935)$ & $436(0.348)$ \\
Buckeye $^{\circledR}$ & 6584 & $6137(0.932)$ & $5544\left(0.903^{\mathrm{a}}\right)$ & $5217\left(0.941^{\mathrm{a}}\right)$ & $165\left(0.278^{\mathrm{a}}\right)$ \\
Prohatch $^{\circledR}$ & 1181 & $1096(0.928)$ & $1012\left(0.923^{\mathrm{a}}\right)$ & $941\left(0.930^{\mathrm{ab}}\right)$ & $27\left(0.321^{\mathrm{ab}}\right)$ \\
African Incubator $^{\circledR}$ & 195 & $190(0.974)$ & $177\left(0.932^{\mathrm{ab}}\right)$ & $169\left(0.955^{\mathrm{ab}}\right)$ & $4\left(0.308^{\mathrm{ab}}\right)$ \\
Combinations & 4691 & $4355(0.928)$ & $3791\left(0.870^{\mathrm{b}}\right)$ & $3510\left(0.926^{\mathrm{b}}\right)$ & $240\left(0.426^{\mathrm{b}}\right)$ \\
Chi $^{2}$ & & 6.498 & 43.684 & 9.971 & 28.024 \\
\hline
\end{tabular}

Critical $\mathrm{Chi}^{2}(P=0.05)$ for 6 degrees of freedom $=7.815$.

${ }^{\mathrm{a}, \mathrm{b}}$ Denote significant $(P<0.05)$ differences in columns between frequencies in brackets.

Table 5 Influence of production year on the pipping success, pipping position, and survival of chicks hatched form eggs produced during three consecutive breeding seasons

\begin{tabular}{lccccc}
\hline & \multicolumn{5}{c}{ Category } \\
\cline { 2 - 6 } Year & Number of eggs & Eggs pipped & $\begin{array}{c}\text { Pipped in correct } \\
\text { position }\end{array}$ & $\begin{array}{c}\text { Survival of } \\
\text { chicks pipped in } \\
\text { correct position }\end{array}$ & $\begin{array}{c}\text { Survival of } \\
\text { chicks pipped in } \\
\text { incorrect } \\
\text { position }\end{array}$ \\
\hline Overall & 12659 & $11780(0.931)$ & $10526(0.894)$ & $9842(0.935)$ & $429(0.342)$ \\
2006 & 5086 & $4644\left(0.913^{\mathrm{a}}\right)$ & $4165\left(0.897^{\mathrm{a}}\right)$ & $3890(0.934)$ & $126\left(0.263^{\mathrm{a}}\right)$ \\
2007 & 3007 & $2826\left(0.940^{\mathrm{b}}\right)$ & $2568\left(0.909^{\mathrm{a}}\right)$ & $2411(0.939)$ & $51\left(0.198^{\mathrm{a}}\right)$ \\
2008 & 4566 & $4310\left(0.944^{\mathrm{b}}\right)$ & $3793\left(0.880^{\mathrm{b}}\right)$ & $3539(0.933)$ & $259\left(0.501^{\mathrm{b}}\right)$ \\
$\mathrm{Chi}^{2}$ & & 40.627 & 15.620 & 0.881 & 94.286 \\
\hline
\end{tabular}

Critical $\mathrm{Chi}^{2}(P=0.05)$ for 6 degrees of freedom $=5.991$.

${ }^{\mathrm{a}, \mathrm{b}}$ Denote significant $(P<0.05)$ differences in columns between frequencies in brackets.

Storage time prior to setting had a significant influence on all traits reported in Table 7 . The proportion of chicks pipped was the highest for eggs stored between two and five days, while it was reduced for chicks that hatched from eggs that were not stored before setting $(P<0.05)$. The best performance in terms of chicks pipping in the correct position, as well as survival of chicks pipping in the correct position, was found for eggs stored for four days. Apart from a reduced pipping percentage, chicks from eggs that were not stored before setting also had a poorer $(P<0.05)$ survival of hatching when pipping in the correct position. The survival of chicks pipping in the incorrect position was independent of the number of days the eggs were stored.

The prolonged storage of eggs before setting leads to malformation in the embryo and to a reduced growth rate of the embryos of the domestic fowl (Fasenko et al., 1992; Meijerhof, 1992) and the ostrich (Malecki et al., 2005). Fasenko (2007) also reported that the embryonic output rate of $\mathrm{CO}_{2}$ from eggs that were stored for a prolonged period was slower than the output of embryos from eggs stored for shorter 
periods.

Previous

Table 6 Influence of percentage water loss up to day 35 of artificial incubation on the pipping success, pipping position, and survival of chicks hatched form eggs produced during three consecutive breeding seasons

\begin{tabular}{|c|c|c|c|c|c|}
\hline \multirow[b]{2}{*}{$\begin{array}{l}\text { Water loss to } 35 \\
\text { days (\% fresh egg } \\
\text { weight) }\end{array}$} & \multicolumn{5}{|c|}{ Category } \\
\hline & Number of eggs & Eggs pipped & $\begin{array}{l}\text { Pipped in correct } \\
\text { position }\end{array}$ & $\begin{array}{c}\text { Survival of } \\
\text { chicks pipped in } \\
\text { correct position }\end{array}$ & $\begin{array}{c}\text { Survival of } \\
\text { chicks pipped in } \\
\text { incorrect } \\
\text { position } \\
\end{array}$ \\
\hline Overall & 12659 & $11780(0.931)$ & $10526(0.894)$ & $9842(0.935)$ & $436(0.348)$ \\
\hline$<7$ & 105 & $72\left(0.686^{\mathrm{a}}\right)$ & $52\left(0.722^{\mathrm{a}}\right)$ & $48\left(0.673^{\mathrm{a}}\right)$ & $1\left(0.050^{\mathrm{ab}}\right)$ \\
\hline $7-8.9$ & 1070 & $948\left(0.886^{\mathrm{b}}\right)$ & $807\left(0.851^{\mathrm{ab}}\right)$ & $806\left(0.850^{b}\right)$ & $32\left(0.230^{\mathrm{a}}\right)$ \\
\hline $9-10.9$ & 2698 & $2512\left(0.931^{\mathrm{d}}\right)$ & $2255\left(0.898^{\mathrm{cd}}\right)$ & $2379\left(0.947^{\mathrm{c}}\right)$ & $90\left(0.350^{\mathrm{ab}}\right)$ \\
\hline $11-12.9$ & 3473 & $3291\left(0.948^{\text {de }}\right)$ & $3024\left(0.919^{d}\right)$ & $3123\left(0.949^{c}\right)$ & $98\left(0.367^{\mathrm{ab}}\right)$ \\
\hline $13-14.9$ & 2878 & $2740\left(0.952^{\mathrm{e}}\right)$ & $2440\left(0.891^{\mathrm{c}}\right)$ & $258\left(0.954^{\mathrm{c}}\right)$ & $127\left(0.423^{b}\right)$ \\
\hline $15-16.9$ & 1542 & $1430\left(0.927^{\mathrm{d}}\right)$ & $1276\left(0.892^{\text {bcd }}\right)$ & $1194\left(0.936^{\mathrm{c}}\right)$ & $60\left(0.390^{\mathrm{ab}}\right)$ \\
\hline $17-18.9$ & 541 & $498\left(0.921^{\mathrm{cde}}\right)$ & $438\left(0.880^{\mathrm{bcd}}\right)$ & $403\left(0.920^{c}\right)$ & $16\left(0.267^{\mathrm{ab}}\right)$ \\
\hline$>19$ & 352 & $289\left(0.821^{\mathrm{ab}}\right)$ & $234\left(0.810^{\mathrm{ab}}\right)$ & $\left(0.816^{\mathrm{ab}}\right.$ & $14\left(0.236^{\mathrm{ab}}\right.$ \\
\hline $\mathrm{Chi}^{2}$ & & 232.956 & 85.359 & 239.118 & 31.926 \\
\hline
\end{tabular}

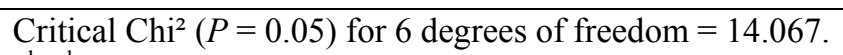

a,b,c,d Denote significant $(P<0.05)$ differences in columns between frequencies in brackets.

Table 7 Influence of duration of pre-incubation storage on the pipping success, pipping position, and survival of chicks hatched form eggs produced in the southern hemisphere

\begin{tabular}{|c|c|c|c|c|c|}
\hline \multirow[b]{2}{*}{ Storage time } & \multicolumn{5}{|c|}{ Category } \\
\hline & Number of eggs & Eggs pipped & $\begin{array}{l}\text { Pipped in correct } \\
\text { position }\end{array}$ & $\begin{array}{l}\text { Survival of } \\
\text { chicks pipped in } \\
\text { correct position }\end{array}$ & $\begin{array}{c}\text { Survival of } \\
\text { chicks pipped in } \\
\text { incorrect } \\
\text { position } \\
\end{array}$ \\
\hline Overall & 12659 & $11780(0.931)$ & $10526(0.894)$ & $9842(0.935)$ & $436(0.348)$ \\
\hline 0 & 1779 & $1608\left(0.904^{\mathrm{a}}\right)$ & $1395\left(0.868^{\mathrm{a}}\right)$ & $1271\left(0.911^{\mathrm{a}}\right)$ & $72(0.338)$ \\
\hline 1 & 1796 & $1669\left(0.929^{\mathrm{ab}}\right)$ & $1479\left(0.886^{\mathrm{ab}}\right)$ & $1378\left(0.932^{\mathrm{ab}}\right)$ & $52(0.274)$ \\
\hline 2 & 1946 & $1818\left(0.934^{b}\right)$ & $1629\left(0.896^{\mathrm{ab}}\right)$ & $1518\left(0.932^{\mathrm{ab}}\right)$ & $72(0.381)$ \\
\hline 3 & 1663 & $1572\left(0.945^{b}\right)$ & $1419\left(0.903^{\mathrm{ab}}\right)$ & $1332\left(0.939^{\mathrm{ab}}\right)$ & $53(0.346)$ \\
\hline 4 & 1808 & $1684\left(0.931^{\mathrm{ab}}\right)$ & $1544\left(0.917^{\mathrm{b}}\right)$ & $1470\left(0.952^{\mathrm{b}}\right)$ & $49(0.350)$ \\
\hline 5 & 1671 & $1577\left(0.944^{b}\right)$ & $1413\left(0.896^{\mathrm{ab}}\right)$ & $1335\left(0.945^{\mathrm{ab}}\right)$ & $65(0.396)$ \\
\hline 6 & 1797 & $1664\left(0.926^{\mathrm{ab}}\right)$ & $1483\left(0.89^{\mathrm{ab}}\right)$ & $1382\left(0.932^{\mathrm{ab}}\right)$ & $66(0.365)$ \\
\hline$>6$ & 199 & $188\left(0.945^{\mathrm{ab}}\right)$ & $164\left(0.872^{\mathrm{ab}}\right)$ & $154\left(0.939^{\mathrm{ab}}\right)$ & $7(0.292)$ \\
\hline $\mathrm{Chi}^{2}$ & & 31.342 & 24.5988 & 23.740 & 7.875 \\
\hline
\end{tabular}

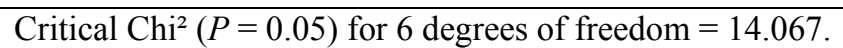

${ }^{\mathrm{a}, \mathrm{b}}$ Denote significant $(P<0.05)$ differences in columns between frequencies in brackets. 
studies have shown that the embryonic survival of ostrich chicks was impaired in eggs that were stored for seven days and longer (Brand et al., 2007), which was consistent with the findings of Ar \& Gefen (1998), Deeming (1996), Wilson et al. (1997) and Horbańczuk (2000). According to Table 7, these limitations were not as evident in near-term chicks in the interval from 35 days of incubation to hatching.

\section{Conclusion}

The present study showed that the frequency of pipping, pipping in the correct position, as well as survival for ostrich chicks pipped in either the correct or incorrect position, were affected by a number of environmental factors. The influence of genotype and female age were absent to very small for the traits analysed, while the effects of water loss, incubator and storage time prior to setting were of greater practical significance. Although season had an effect on the pipping performance of near-term ostrich chicks, conflicting results were reported in some instances. For both year and season, the present study clearly shows that data needs to be recorded for more years to assess the possible long-term trends on the pipping performance in near-term ostrich eggs. Some of the factors noted have direct and immediate application, such as a preference not to move eggs between incubators and the setting of eggs after being stored for a short period ( 2 - 3 days). Incubators should also be set to optimally control water loss within the ranges required for optimal hatching success. The above-mentioned factors should all be considered when planning commercial ostrich husbandry and artificial incubation operations.

\section{References}

Ar, A., 1996. Requirements for successful artificial incubation of ostrich eggs. In: Improving Our Understanding of Ratites in Farming Environment. Ed. Deeming, D.C., Proc. Int. Conf., Manchester, England. pp. 131-144.

Ar, A. \& Gefen, E., 1998. Further improving hatchability in artificial incubation of ostrich eggs. In: Ratites in a Competitive World. Proc. $2^{\text {nd }}$ Int. Ratite Cong., Oudtshoorn, South Africa. pp. 141-147.

Badley, A.R., 1997. Fertility, hatchability and incubation of ostrich (Struthio camelus) eggs. Poult. Avian Biol. Rev. 8, 53-76.

Blood, J.R., Van Schalkwyk, S.J., Cloete, S.W.P. \& Brand, Z., 1998. Embryonic deaths in relation to water loss of artificially incubated ostrich eggs. Proc. $2^{\text {nd }}$ Int. Ratite Cong., Oudtshoorn, South Africa. pp. 148-151.

Brand, M.M., Cloete, S.W.P., Hoffman, L.C. \& Muller, M., 2005. A comparison of live weights, body measurements and reproductive traits in Zimbabwean Blue ostriches (Struthio camelus australis) and South African Black ostriches (S. camelus var. domesticus). Ed. Carbajo, E., Proc. ${ }^{\text {rd }}$ Int. Ratite Sci. Sym. \& XII Wrld Ostrich Cong., Madrid, Spain. pp. 73-80.

Brand, Z., Cloete, S.W.P., Brown, C.R. \& Malecki, I.A., 2007. Factors related to shell deaths during artificial incubation of ostrich eggs. J. S. Afr. Vet. Ass. 78, 195-200.

Brand, Z., Cloete, S.W.P., Brown, C.R. \& Malecki, I.A., 2008a. Systematic factors that affect ostrich egg incubation traits. S. Afr. J. Anim. Sci. 38, 315-325.

Brand, Z., Cloete, S.W.P., Malecki, I.A. \& Brown, C.R., 2008b. Genetic relationships between water loss and shell deaths in ostrich eggs, assessed as traits of the female. Aust. J. Exp. Agric, 48, 1326-1331.

Brown, C.R., Peinke, D. \& Loveridge, A., 1996. Mortality in near-term ostrich embryos during artificial incubation. Br. Poult. Sci. 37, 73-85.

Bunter, K.L., 2002. The genetic analysis of reproduction and production traits recorded for farmed ostriches (Struthio camelus). PhD dissertation, University New England, Armidale, Australia.

Bunter, K.L. \& Cloete, S.W.P., 2004. Genetic parameters for egg-, chick- and live-weight traits recorded in farmed ostriches (Struthio camelus). Livest. Prod. Sci. 91, 9-22.

Chowdhury, M.M.I., Ashraf, A., Mondal, S.P., Mondal, N.M.A.A.M. \& Hasan, M.M., 2004. Effect of season on the hatchability of duck eggs. Int. J. Poult. Sci. 3, 419-421.

Cloete, S.W.P., Lambrecht, H., Punt, K. \& Brand, Z., 2001. Factors related to high levels of ostrich chick mortality from hatching to 90 days of age in an intensive rearing system. J. S. Afr. Vet. Ass. 72, 197202.

Cloete, S.W.P., Bunter, K.L. \& Van Schalkwyk, S.J., 2002. Progress towards a scientific breeding strategy for ostriches. Proc. $7^{\text {th }}$ Wrld. Cong. Montpellier, France. Genet. Appl. Livest. Prod. 30, 561-568. 
Cloete, S.W.P., Bunter, K., Lambrechts, H., Brand, Z., Swart, D. \& Greyling, J.P.C., 2006a. Variance components for live weight, body measurements and reproductive traits of pair-mated ostrich females. Br. Poult. Sci. 47, 147-158.

Cloete, S.W.P., Scholtz, A., Brand, Z. \& Cloete, S.W.P., 2006b. A preliminary study on the application of image analysis for the measurement of ostrich eggshell traits. S. Afr. J. Anim. Sci. 36, 155-159.

Davis, T.A., Shen, S.S. \& Ackerman, R.A., 1988. Embryonic osmoregulation: consequences of high and low water loss during incubation of the chicken egg. J. Exper. Zool. 245, 144-156.

Deeming, D.C., 1994. When to help ostrich chicks to hatch. The Ostrich News. July 1994. pp. 60-61.

Deeming, D.C., 1995a. Factors affecting hatchability during commercial incubation of ostrich (Struthio camelus) eggs. Br. Poult. Sci.36, 51-65.

Deeming, D.C., 1995b. The hatching sequence of Ostrich (Struthio camelus) embryos with notes on development as observed by candling. Br. Poult. Sci. 36, 67-78.

Deeming, D.C., 1996. Production, fertility and hatchability of ostrich (Struthio camelus) eggs on a farm in the United Kingdom. Anim. Sci. 63, 329-336.

Deeming, D.C., Ayres, L. \& Ayres, F.J., 1993. Observations on the first commercial production of ostrich (Struthio camelus) eggs in the UK: Incubation. The Vet. Rec., 132, 602-607.

Fasenko, G.M., 2007. Egg Storage and the embryo. Poult. Sci. 86, 1020-1024.

Fasenko, G.M., Robinson, F.E., Hardin, R.T. \& Wilson, J.L., 1992. Effect of duration of egg storage period. Poult. Sci. 72, 2129-2132.

Hassan, S.M., Siam, A.A., Mady, M.E. \& Cartwright, A.L., 2005. Eggs storage period and weight effects on hatchability of ostrich (Struthio camelus) eggs. Poult. Sci. 84, 1908-1912.

Horbańczuk, J.O., 2000. Improving the technology of artificial incubation of ostrich (Struthio camelus) eggs with reference to biological aspects. Prace i Materialy Zootechniczne, Zeszyl Specjalny. 10, 1-90,102.

Horbaňczuk, J.O., Sales, J., Celeda, T. \& Zieba, G., 1999. Effect of relative humidity on the hatchability of ostrich (Struthio camelus) eggs. Czech J. Anim. Sci. 44, 303-307.

Ipek, A. \& Sahan, U., 2004. Effect of breeder age and breeding season on egg production and incubation in farmed ostriches. Br. Poult. Sci. 45, 643-647.

Lambrechts, H., 2004. Reproductive efficiency of ostriches (Struthio camelus). PhD (Agric.) dissertation, University of the Free State, Bloemfontein, South Africa.

Meijerhof, R., 1992. Pre-incubation holing of hatchling eggs. Wrld Poult. Sci. J. 48, 57-68.

Malecki, I.A., Horbanczuk, J.O., Reed, C.E. \& Martin, G.B., 2005. The ostrich (Struthio camelus) blastoderm and embryo development following storage of eggs at various temperatures. Br. Poult. Sci. 46, 652-660.

Musara, C., Chidhumo, P. \& Murinzi, N., 1999. A retrospective analysis of water balance and hatchability in artificially incubated ostrich (Struthio camelus) eggs. Zim. Vet. J. 30, 75-84.

Van Schalkwyk, S.J., Cloete, S.W.P. \& De Kock, J.A., 1996. Repeatability and phenotypic correlation for body weight and reproduction in commercial ostrich breeding pairs. Br. Poult. Sci. 37, 953-962.

Van Schalkwyk, S.J., Brand, Z., Cloete, S.W.P. \& Blood, J.R., 1998. The influence of different disinfectant protocols on the hatching performance of ostrich chicks. In: Ratites in a Competitive World. Proc. $2^{\text {nd }}$ Int. Ratite Cong., Oudtshoorn, South Africa. pp. 157-159.

Van Schalkwyk, S.J., Brand, Z., Cloete, S.W.P. \& Brown, C.R., 1999. Effect of time of egg collection and pre-incubation treatment on blastoderm development and embryonic mortality in ostrich embryos. S. Afr. J. Anim. Sci. 29, 154-163.

Van Ark, H., 1990. Freq.exe - For the comparison of frequencies. Datametrical Services, Department of Agriculture, Private Bag X116, Pretoria, 0001, South Africa.

Wilson, H.R., Eldred, A.R. \& Wilcox, C.J., 1997. Storage time and ostrich egg hatchability. Appl. Poult. Sci. 6, 216-220. 